\title{
Expression and regulation of glucocorticoid-induced leucine zipper in the developing anterior pituitary gland
}

\author{
Laura E Ellestad ${ }^{1,2}$, Stefanie A Malkiewicz ${ }^{2}$, H David Guthrie ${ }^{3}$, Glenn R Welch ${ }^{3}$ \\ and Tom E Porter ${ }^{1,2}$ \\ ${ }^{1}$ Molecular and Cell Biology Program, University of Maryland, College Park, Maryland 20742, USA \\ ${ }^{2}$ Department of Animal and Avian Sciences, University of Maryland, Building 142, Room 1403, College Park, Maryland 20742, USA \\ ${ }^{3}$ Animal Biosciences and Biotechnology Laboratory, Agricultural Research Service, US Department of Agriculture, Beltsville, Maryland 20705, USA \\ (Correspondence should be addressed to T E Porter; Email: teporter@umd.edu)
}

\begin{abstract}
The expression profile of glucocorticoid-induced leucine zipper (GILZ) in the anterior pituitary during the second half of embryonic development in the chick is consistent with in vivo regulation by circulating corticosteroids. However, nothing else has been reported about the presence of GILZ in the neuroendocrine system. We sought to characterize expression and regulation of GILZ in the chicken embryonic pituitary gland and determine the effect of GILZ overexpression on anterior pituitary hormone levels. Pituitary GILZ mRNA levels increased during embryogenesis to a maximum on the day of hatch, and decreased through the first week after hatch. GILZ expression was rapidly upregulated by corticosterone in embryonic pituitary cells. To determine whether GILZ regulates hormone gene expression in the developing anterior pituitary, we overexpressed GILZ in embryonic pituitary cells and measured mRNA for the major pituitary hormones. Exogenous GILZ increased prolactin mRNA above basal levels, but not as high as that in corticosterone-treated cells, indicating that GILZ may play a small role in lactotroph differentiation. The largest effect we observed was a twofold increase in FSH $\beta$ subunit in cells transfected with GILZ but not treated with corticosterone, suggesting that GILZ may positively regulate gonadotroph development in a manner not involving glucocorticoids. In conclusion, this is the first report to characterize avian GILZ and examine its regulation in the developing neuroendocrine system. We have shown that GILZ is upregulated by glucocorticoids in the embryonic pituitary gland and may regulate expression of several pituitary hormones.
\end{abstract}

Journal of Molecular Endocrinology (2009) 42, 171-183

\section{Introduction}

In a study profiling gene expression during cellular differentiation of the chicken embryonic pituitary gland, our laboratory identified glucocorticoid-induced leucine zipper (GILZ) as an anterior pituitary transcript that increased between embryonic day (e) 12 and e17 (Ellestad et al. 2006). This expression pattern is consistent with in vivo regulation of GILZ in the anterior pituitary by glucocorticoids, as circulating corticosteroids increase between e12 and e17 in the developing chicken embryo (Scott et al. 1981, Jenkins et al. 2007, Porter et al. 2007). Corticosterone (CORT), the predominant glucocorticoid in rodents and birds, increases 100-fold during chicken embryonic development, from subnanomolar concentrations on e10 $(0 \cdot 3 \mathrm{nM})$ to e17 $(40 \mathrm{nM})$, when the levels are highest (Jenkins et al. 2007, Porter et al. 2007). Corticosteroids are thought to play a role in the initiation of hormone expression during pituitary cell ontogeny in both mammals and birds. In both rats and chickens, CORT stimulates GH and prolactin (PRL) expression during somatotroph and lactotroph differentiation respectively (Hemming et al. 1984, Nogami et al. 1995, Morpurgo et al. 1997, Dean \& Porter 1999, Dean et al. 1999, Bossis \& Porter 2000, Fu \& Porter 2004). Glucocorticoids also repress pro-opiomelanocortin (POMC) expression during negative feedback on adrenocorticotropic hormone (ACTH) release from pituitary corticotrophs (Drouin et al. 1989), although when this feedback is established during development is not clear. In the pituitary, GILZ may be mediating effects of glucocorticoids as well as exhibiting independent effects in this tissue.

GILZ was first identified as a glucocorticoid-induced transcript in mouse thymocytes, and its expression was initially thought to be restricted to lymphoid tissues (D'Adamio et al. 1997). Subsequently, GILZ has been shown to be widely expressed and has been detected in numerous tissues and cell types (Cannarile et al. 2001, Berrebi et al. 2003, Kolbus et al. 2003, Shi et al. 2003, Zhao et al. 2006). GILZ is thought to be a transcription factor and has been shown experimentally to bind DNA (Shi et al. 2003) as well as interact with other leucine zipper transcription factors such as c-Fos and c-Jun (Mittelstadt \& 
Ashwell 2001). GILZ has also been shown to mediate signaling and transcriptional events through extranuclear protein-protein interactions with Ras, Raf-1, and nuclear factor $\mathrm{\kappa B}$ (Ayroldi et al. 2001, 2002, 2007). GILZ has been implicated in apoptosis (D'Adamio et al. 1997, Bruscoli et al. 2006) and cell proliferation (Ayroldi et al. 2007), immunosuppression (Berrebi et al. 2003), sodium transport (Soundararajan et al. 2005), parturition (Zhao et al. 2006), and cell fate choice (Shi et al. 2003, Levine et al. 2007, Zhang et al. 2007).

To our knowledge, no studies investigating the presence or regulation of GILZ in the neuroendocrine system, a well-established target of glucocorticoid action, have been conducted. Further, GILZ has not been characterized in an avian species, and it is unknown whether avian GILZ is regulated in a manner similar to mammalian GILZ. The chicken has several advantages over traditional mammalian models for studying pituitary gland development, including the ability to precisely control the beginning of embryonic development and therefore perform experiments with hundreds of pituitary glands at a given age. Pituitary development is highly conserved among vertebrates; therefore, understanding regulation and potential action of GILZ in the developing pituitary gland of the chick embryo will provide information about pituitary development that is applicable to mammalian species as well. The objectives of this study were to determine the sequence and tissue distribution of chicken GILZ mRNA, to determine GILZ ontogeny and regulation by glucocorticoids in the embryonic pituitary gland, and to determine whether GILZ plays a role in regulating expression of the anterior pituitary hormones.

\section{Materials and methods}

\section{Animals and pituitary collection}

Broiler strain chicken embryos used for these experiments were purchased from Allen's Hatchery (Seaford, DE, USA). Eggs were placed in a $37.5{ }^{\circ} \mathrm{C}$ humidified incubator on embryonic day (e) 0 and removed on the appropriate day of the 21-day incubation period for each experiment. For cell culture experiments, pituitary glands were isolated with a dissecting microscope from embryos on e11 and dissociated into individual cells using trypsin digestion and mechanical agitation (Porter et al. 1995). Anterior pituitaries from $\sim 60$ embryos were isolated and pooled for each of the four replicate trials of a given experiment $(n=4)$. For the GILZ ontogeny experiment, whole anterior pituitary glands were collected from e10, e12, e14, e16, e18, e20, post-hatch day (d) 1, d3, d5, and d7 birds using a dissecting microscope. To yield adequate RNA from each developmental age, pituitaries from 3 e10, 2 e12, 2 e14, and 2 e16 embryos were pooled for each replicate sample; one pituitary per replicate was used for the older ages. Four replicate samples were collected for each age $(n=4)$. Pituitaries were immediately frozen in liquid $\mathrm{N}_{2}$ and stored at $-80{ }^{\circ} \mathrm{C}$ until RNA extraction. All procedures were approved by the Institutional Animal Care and Use Committee at the University of Maryland.

\section{Sequencing of chicken GILZ cDNA and comparison with other species}

The putative chicken GILZ clone was part of a neuroendocrine cDNA library used to construct a custom cDNA microarray and was initially identified through random sequencing of the library in combination with BLAST comparisons (Cogburn et al. 2004, Carre et al. 2006, Ellestad et al. 2006). The plasmid containing chicken GILZ (pgp1n.pk005.a10, GenBank accession numbers BI391625) was purified according to a standard protocol (Sambrook et al. 1989), and the clone was sequenced in its entirety in both directions. In order to fully sequence the insert, three sequencing reactions were performed on each of the sense and antisense strands. Oligonucleotide primers (Sigma Genosys) used for sequencing were Sp6microarray+, Gilzsense1, and Gilzsense 2 for the forward reactions, and T7microarray + , Gilzantisense1, and Gilzantisense2 for the reverse reactions (Table 1). Sequencing reactions were performed by the University of Maryland's Center for Biosystems Research DNA Sequencing Facility with AmpliTaq-FS DNA polymerase and Big Dye terminators with dITP in an Applied Biosystems DNA Sequencer (Model 3100; Foster City, CA, USA). Overlapping sequences were assembled into the full-length chicken GILZ cDNA using Vector NTI 9.0 (Invitrogen), and the same software was used to make comparisons between chicken GILZ nucleotide and predicted amino acid sequences with those for human (accession numbers NM_004089 and NP_004080), mouse (accession numbers NM_010286 and NP_034416), dog (accession numbers XM_549177 and XP_549177), zebrafish (accession numbers XM_703382 and XP_708474), and Xenopus (accession numbers BC043841 and AAH43841) obtained from GenBank. Human, mouse, and Xenopus sequences are cloned mRNAs, and $\operatorname{dog}$ and zebrafish sequences are predicted transcripts based on computational analysis. Biology Workbench (http:// workbench.sdsc.edu/) was used to create the alignment (CLUSTALW tool), color-coding (BOXSHADE tool), and unrooted phylogenetic tree diagrams shown in Fig. 1.

\section{Cell culture}

Hormones and other chemicals were obtained from Sigma-Aldrich, and cell culture reagents were obtained from Invitrogen. Cells were maintained in a $37.5{ }^{\circ} \mathrm{C}, 5 \%$ 
A

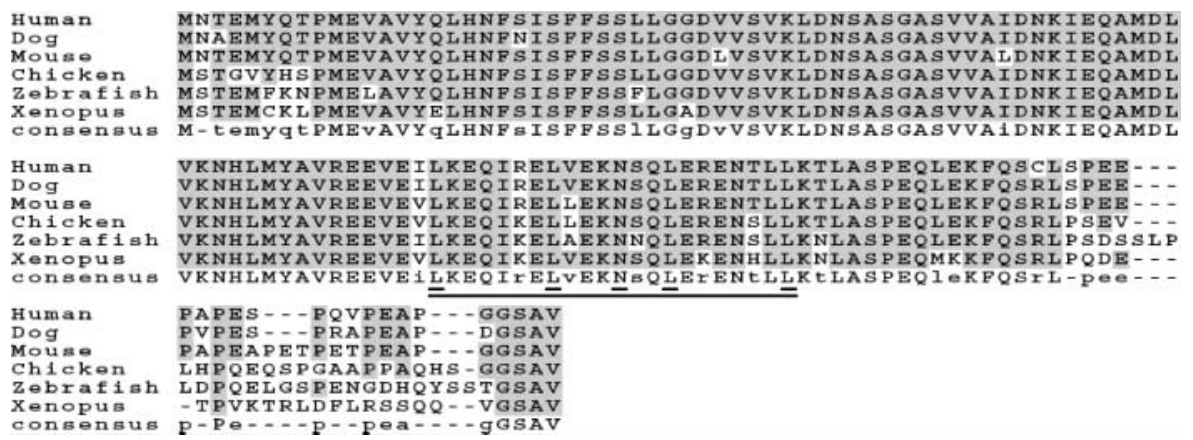

Human

Dog

Chicke

Zebrafis

consensu

Human

Dog

consensu

Human

Mous

Zebrafi

xenopus

Figure 1 Chicken glucocorticoid-induced leucine zipper (GILZ) is highly homologous with GILZ from other vertebrate species. (A) Predicted amino acid sequence for chicken, human, dog, mouse, zebrafish, and Xenopus GILZ were aligned, and the regions of amino acid sequence that are identical with the consensus derived from all species are shaded. The leucine zipper region (black underline) is characterized by four leucine residues at positions $76,83,90$, and 97 and one asparagine at position 87 (double underlines). (B) Unrooted phylogenetic tree of GILZ amino acid sequences from the species listed in (A). The length of the lines connecting the species indicates the predicted evolutionary distance.

Table 1 Primers used in chicken glucocorticoid-induced leucine zipper (GILZ) sequencing, northern blotting, reverse transcription (RT)-PCR, and quantitative real-time RT-PCR

$$
\text { Primer sequence }\left(5^{\prime} \rightarrow 3^{\prime}\right)
$$

Primer name
Anchored-
dT-one-V
ACTB_span4_fwd
ACTB_span4_rev
FSHbeta_
span2_fwd
FSHbeta_
span2_rev
GH_span4_fwd
GH_span4_rev
Gilzsense1
Gilzsense329
Gilzsense2
Gilzfwd2
Gilzantisense2
Gilzrev2
Gilzantisense1
GSU_span4_fwd
GSU_span4_rev
LHbeta_fwd
LHbeta_rev
POMC_3'exon3'
fwd
POMC_3'exon3'
rev
PRL_span4_fwd
PRL_span4_rev
Sp6microarray+
T7microarray+
TSHbeta_-
span2_fwd
TSHbeta_
span2_rev

CGGAATTCTTTTTTTTTTTTTTTTTTTTV

CAGGATGCAGAAGGAGATCACA TAGAGCCTCCAATCCAGACAGAGTA AGCAGTGGAAAGAGAAGAATGTGA

TGTTTCATACACAACCTCCTTGAAG

CACCTCAGACAGAGTGTTTGAGAAA CAGGTGGATGTCGAACTTATCGT CGTGAGAACAGCCTCCTGAA AGAAGTTCCAGTCACGGCTC ATCGTGCTGTCCATGGGGAT ACCCAAAGCCGGACTTGAG AAGGCAGACAGGTGGGGTTC CGCATAGACACAGCTACAGAAACAC TGTACACAACCACATCACCG CTTTCCCAGATGGAGAATTTCTCA ACCTGTTCTCCCCTAGCTTGC GGATGCCCCCAATGTATGG TCCCGCGTCCTGCAGTA CGCTACGGCGGCTTCA

\section{TCTTGTAGGCGCTTTTGACGAT}

AGGAATGGAGAAAATAGTTGGGC TCATTTCCAGCATCACCAGAAT GGCCTATTTAGGTGACACTATAG GCTTATAATACGACTCACTATAGGG ACTGCCTGGCCATCAACAC

ACACGTTTTGAGACAGAGCACTTTT

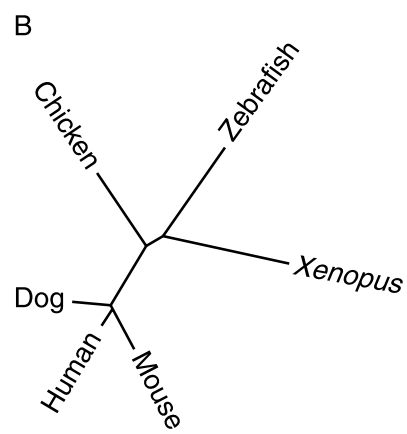

$\mathrm{CO}_{2}$ atmosphere. Dispersed pituitary cells were cultured in serum-free medium (DMEM/F12) supplemented with $0 \cdot 1 \%$ BSA, $5 \mu \mathrm{g} / \mathrm{ml}$ human insulin, $5 \mu \mathrm{g} / \mathrm{ml}$ human transferrin, $100 \mathrm{U} / \mathrm{ml}$ penicillin $\mathrm{G}$, and $100 \mu \mathrm{g} / \mathrm{ml}$ streptomycin sulfate.

For the GILZ mRNA induction experiments, e11 pituitary cells $\left(1 \times 10^{6} /\right.$ well $)$ cultured in 12-well plates (Corning Incorporated, Corning, NY, USA) for $24 \mathrm{~h}$ were treated for the final $1 \cdot 5,3,6$, or $12 \mathrm{~h}$ with CORT $(1 \mathrm{nM})$ in the absence and presence of cycloheximide (CHX; $10 \mu \mathrm{g} / \mathrm{ml}$ ). In wells receiving CHX plus CORT, cells were pretreated for $1.5 \mathrm{~h}$ with CHX prior to addition of CORT. Untreated cells and cells receiving CHX alone for $1.5 \mathrm{~h}$ served as controls. In all experiments, cells were harvested by retrypsinization and stored at $-80^{\circ} \mathrm{C}$ until total RNA was extracted.

For GILZ overexpression experiments, dispersed e11 anterior pituitary cells $\left(3 \times 10^{6} /\right.$ well $)$ were co-transfected with $2 \mu \mathrm{g}$ golgi-targeted green fluorescent protein (GFP) expression vector (Pecot \& Malhotra 2004) and either $2 \mu \mathrm{g}$ empty expression vector (pCMVSport6.1; Invitrogen) or $2 \mu \mathrm{g}$ GILZ-expression vector (pgp1n.pk005.a10) for $6 \mathrm{~h}$ using Lipofectamine 2000 (Invitrogen) and Opti-MEM I medium. Cells were transfected in suspension for $2 \mathrm{~h}$ and then plated into 6 -well culture plates for the remaining $4 \mathrm{~h}$. GFP was used to assess transfection efficiency and as a marker to isolate transfected cells using flow cytometric cell sorting. Subsequently, transfection medium was replaced with culture medium, and cells were cultured for $36 \mathrm{~h}$ longer, during which CORT $(1 \mathrm{nM})$ was added for the final $16 \mathrm{~h}$. Cells were harvested by retrypsinization and resuspended in $1 \mathrm{ml}$ culture medium for flow cytometric analysis and sorting. 


\section{Flow cytometry}

Successfully transfected cells in GILZ overexpression studies were identified by flow cytometric detection of GFP (fluorescence detection 530/30 nm). GFP-positive cells were sorted using a high performance flow cytometer and cell sorter (MoFlo; DakoCytomation, Carpinteria, CA, USA) equipped with an argon ion laser tuned to $488 \mathrm{~nm}$ (Innova 300, Coherent, Palo Alto, CA, USA). To enhance recovery of sorted cells, the enrichment sort mode was used. Sorting of the GFPpositive population $(19 \cdot 3 \%$ of cells; $n=4$ replicate experiments) resulted in collection of $\sim 70000$ GFPpositive cells per group. Additionally, GFP-negative cells were collected, and both were pelleted at $1000 \mathrm{~g}$ for $10 \mathrm{~min}$ and snap-frozen in liquid nitrogen. Cells were stored at $-80^{\circ} \mathrm{C}$ until total RNA was extracted.

\section{Northern blotting}

Total RNA samples isolated from indicated tissues using TRIZOL (Invitrogen) were quantified by measuring the absorbance at $260 \mathrm{~nm}$ with u.v. spectrophotometer. RNA $(10 \mu \mathrm{g})$ was separated by formaldehyde agarose gel $(1 \%)$ electrophoresis, transferred to a Zeta-Probe Blotting Membrane (Bio-Rad), and cross-linked to the membrane with a u.v. Stratalinker (Stratagene, La Jolla, CA, USA). The membrane was probed with a ${ }^{32} \mathrm{P}-$ labeled full-length chicken GILZ cDNA probe generated by PCR using the pgp1n.pk005.a10 plasmid with Sp6microarray $+/ \mathrm{T} 7$ microarray + primers (SigmaGenosys, Table 1) and the following conditions: initial denaturation of $94^{\circ} \mathrm{C}$ for $3 \mathrm{~min}$; 35 cycles of $94^{\circ} \mathrm{C}$ for $45 \mathrm{~s}, 52^{\circ} \mathrm{C}$ for $45 \mathrm{~s}$, and $72{ }^{\circ} \mathrm{C}$ for $3 \mathrm{~min}$; and a final extension of $72{ }^{\circ} \mathrm{C}$ for $7 \mathrm{~min}$. The labeled PCR product was purified with a spin column-30 (Sigma-Aldrich) and hybridized to the membrane overnight at $65^{\circ} \mathrm{C}$ using PerfectHyb Plus 1X Hybridization Buffer (SigmaAldrich). The membrane was washed twice with $2 \times$ SSC and $0.1 \%$ SDS at room temperature for $10 \mathrm{~min}$ and thrice with $0 \cdot 2 \times$ SSC and $0.1 \%$ SDS at $65^{\circ} \mathrm{C}$ for $10 \mathrm{~min}$. Bands were visualized using a phosphorimager (Molecular Dynamics PhosphorImager; Amersham Biosciences). The membrane was then stripped with $0.02 \times$ SSC and $0.1 \%$ SDS at $90{ }^{\circ} \mathrm{C}$ and re-hybridized with a ${ }^{32} \mathrm{P}$-labeled chicken $\beta$-actin (ACTB) probe described previously (Fu \& Porter 2004).

\section{Reverse transcription-PCR (RT-PCR) and 3'-rapid amplification of CDNA ends (RACE)}

Total RNA $(2 \mu \mathrm{g})$ was reversed transcribed $(20 \mu \mathrm{l}$ reactions) using SuperScript III Reverse Transcriptase (Invitrogen) and either a GILZ-specific reverse primer (GILZantisense1; Table 1; Sigma Genosys) for standard RT-PCR or the Anchored-dT-one-V primer (Table 1;
Sigma Genosys) for 3'-RACE. As a negative control for genomic DNA contamination, a reaction was conducted with each sample in which all components were added except reverse transcriptase $(\mathrm{RT}-)$. For standard RT-PCR, the RT reactions were diluted tenfold prior to PCR analysis using GILZsense1 and GILZantisense2 primers (Table 1; Sigma Genosys). PCR cycling parameters were as follows: $94{ }^{\circ} \mathrm{C}$ for $3 \mathrm{~min}$; 35 cycles of $94^{\circ} \mathrm{C}$ for $45 \mathrm{~s}, 59 \cdot 5^{\circ} \mathrm{C}$ for $45 \mathrm{~s}$, and $72^{\circ} \mathrm{C}$ for $3 \mathrm{~min}$; and a final extension at $72^{\circ} \mathrm{C}$ for $7 \mathrm{~min}$. To perform $3^{\prime}$-RACE, two consecutive PCRs were conducted. In the first, undiluted cDNA was amplified using GILZsense1 and AnchoreddT-one-V primers (Sigma-Genosys). This reaction was then purified with a spin column-100 (Sigma-Aldrich) and diluted 1:1000 for subsequent amplification using GILZfwd2 and Anchored-dT-one-V primers. PCRs were conducted as for RT-PCR, except the annealing temperature was $48^{\circ} \mathrm{C}$. Products were visualized using agarose gel (1\%) electrophoresis and ethidium bromide staining and sequenced to confirm they were GILZ.

\section{Quantitative real-time RT-PCR (qRT-PCR)}

Total RNA was extracted from caudal and cephalic pituitary lobes from late embryonic chicks or cultured cells with the RNeasy Mini Kit (Qiagen) and quantified using the Quant-iT RiboGreen RNA Quantitation Reagent (Invitrogen). RNA (20 ng) isolated from flow cytometric-sorted GFP-positive cells was amplified with the procedure (Phillips \& Eberwine 1996) and modifications (Porter \& Ellestad 2005, Ellestad et al. 2006) described elsewhere. Two-step qRT-PCR was used to quantify mRNA levels for ACTB, GH, PRL, POMC, $\alpha$-glycoprotein subunit ( $\alpha$ GSU), TSH $\beta$ subunit (TSH $\beta)$, LH $\beta$ subunit (LH $\beta)$, FSH $\beta$, and GILZ, as appropriate. RT reactions $(20 \mu \mathrm{l})$ were carried out using SuperScript III (Invitrogen) with random primers (Invitrogen) for amplified RNA (200 ng), or the Anchored-dT-one-V primer (Sigma Genosys) with T-RNA (500 ng) for all others. As a negative control for genomic DNA contamination, a pool of all the RNA from a given experiment was made and the reaction conducted as the others except reverse transcriptase was not added. To control for potential GILZ plasmid carryover through the RNA extraction, a pool of RNA from cells transfected with the GILZ-expression vector was also made for the GILZ overexpression studies, and the reaction conducted as the others except reverse transcriptase was not added. All RT reactions were diluted to $100 \mu \mathrm{l}$ prior to PCR analysis. Primers (Sigma Genosys) used in the PCRs were designed with Primer Express Software (Applied Biosystems) and are listed in Table 1 . PCRs $(20 \mu \mathrm{l})$ contained $2 \mu \mathrm{l}$ diluted cDNA, $400 \mathrm{nM}$ each primer, PCR buffer, $0 \cdot 12 \mathrm{U} / \mu \mathrm{l}$ Taq Polymerase, $200 \mathrm{nM}$ dNTPs, $40 \mathrm{nM}$ fluorescein (Invitrogen), and SYBR Green I Nucleic Acid Gel Stain 
(Invitrogen) diluted 1:10 000 and were carried out in the MyiQ Single-Color Real-Time PCR Detection System (Bio-Rad). A two-step PCR cycle was used: initial denaturation at $95{ }^{\circ} \mathrm{C}$ for 5 min followed by 40 cycles of $95^{\circ} \mathrm{C}$ for $15 \mathrm{~s}$ and $60{ }^{\circ} \mathrm{C}$ for $60 \mathrm{~s}$. Dissociation curve analysis and gel electrophoresis were conducted to ensure that a single PCR product of appropriate size was amplified in each reaction and absent from the no RT controls. Except for the developmental ontogeny experiments, in which data were analyzed as previously described (Ellestad et al. 2006), the amount of mRNA for each target gene was normalized to the amount of ACTB mRNA using the following equation: $\Delta C_{\mathrm{t}}=\left(C_{\mathrm{t} \text { no RT }}-C_{\mathrm{t} \text { sample }}\right)_{\text {target }}-\left(C_{\mathrm{t} \text { no RT }}-C_{\mathrm{t}} \text { sample }\right)_{\mathrm{ACTB}}$. The $C_{\mathrm{t}}$ value is the threshold cycle when the amount of amplified product reaches a fixed threshold for fluorescence due to binding of SYBR green to the double-stranded PCR product. Data were then transformed using the following equation mRNA level $=2^{\Delta C_{\mathrm{t}}}$.

For the caudal and cephalic pituitary lobe expression studies, the transformed value for each sample was divided by the mean of the transformed value for the lobe with the highest expression level for a particular gene. Data for each gene are expressed relative to the lobe with the highest expression level. When GILZ was measured during pituitary development, the transformed value for each value was divided by the mean of the transformed value for $\mathrm{d} 1$, such that data are expressed relative to $d 1$, when GILZ expression was found to be highest. For cell culture experiments, the transformed value for each sample was divided by the mean of the transformed value for the basal wells in each experiment such that data are presented as a fold induction in mRNA when compared with basal levels (receiving no treatment and transfected with empty vector, as appropriate).

\section{Data analysis}

The qRT-PCR data, expressed as fold induction relative to basal or relative to pituitary lobe or age with the highest levels for a given gene, were $\log _{2}$-transformed prior to statistical analysis. All data were analyzed by ANOVA using the MIXED models procedure of SAS (SAS Institute, Cary, NC, USA), and differences between groups were determined using the test of least significant difference (PDIFF; SAS).

\section{Results}

\section{Chicken GILZ is highly homologous to GILZ in other vertebrate species}

We identified GILZ as an anterior pituitary transcript that is upregulated during the second half of embryogenesis in the chick using a neuroendocrine system cDNA microarray (Ellestad et al. 2006). As an avian homolog for GILZ has never been reported, we sequenced the cDNA insert of the GILZ clone used to print the microarray (GenBank accession number BI391625) in its entirety in both directions. This sequence was then compared with available GILZ sequences from other species (Table 2 and Fig. 1). Chicken GILZ mRNA (GenBank accession number DQ917420) was determined to be $1118 \mathrm{bp}$ long and encode a predicted protein consisting of 139 amino acids. Along the entire length of chicken GILZ cDNA, there is $55-60 \%$ identity with human, mouse, dog, zebrafish, and Xenopus GILZ; however, comparisons among the coding regions indicate a much higher identity of $75-80 \%$. Similarly, the protein homology between chicken GILZ and other vertebrates is high (75-80\%), especially when positive amino acid substitutions are considered (80-85\%). Importantly, chicken GILZ contains the leucine zipper motif characterized by four conserved leucine residues and one conserved asparagine (Fig. 1A). Phylogenetically, chicken GILZ lies between mammalian and nonmammalian vertebrate species (Fig. 1B). A notable difference is that chicken GILZ contains a substantial truncation of $\sim 500 \mathrm{bp}$ in the $3^{\prime}$-untranslated region compared with that in other vertebrates. We verified through northern blotting that the size of the major chicken GILZ transcript in all tissues examined is $1 \cdot 1 \mathrm{~kb}$ (Fig. 2A). The apparent discrepancy in transcript size in various tissues was due to differences in migration of different RNA samples through the gel and does not represent alternative splicing in the different tissues, as the band detected for ACTB was also shifted in the same direction in those samples. Most notably, the transcripts for GILZ and ACTB detected in the heart, liver, and brain appear larger than those in the other tissues, but are not. The difference in migration of RNA extracted from these tissues may be due to higher levels of impurities in the samples, possibly glycogen, resulting from higher levels of this compound in the starting material. In order to further confirm the presence of this truncation and the length of the transcript, $3^{\prime}$ RACE was performed with two sequential GILZ sense primers and an oligo-dT primer (Table 1 ). As is evident from the picture, the first reaction yielded a smear surrounding the predicted size $(789 \mathrm{bp})$ and the second reaction yielded a clean band of appropriate size (407 bp), which was sequenced and confirmed to be GILZ. This demonstrated that chicken GILZ is indeed shorter in the $3^{\prime}$-untranslated region than mammalian GILZ (Fig. 2D). Further, there is a polyadenylation signal (AAUAAA) just upstream of the 3 -end of our sequence. These results indicate that the major form of chicken GILZ in the tissues examined contains this 3 -trunctation, and may imply 


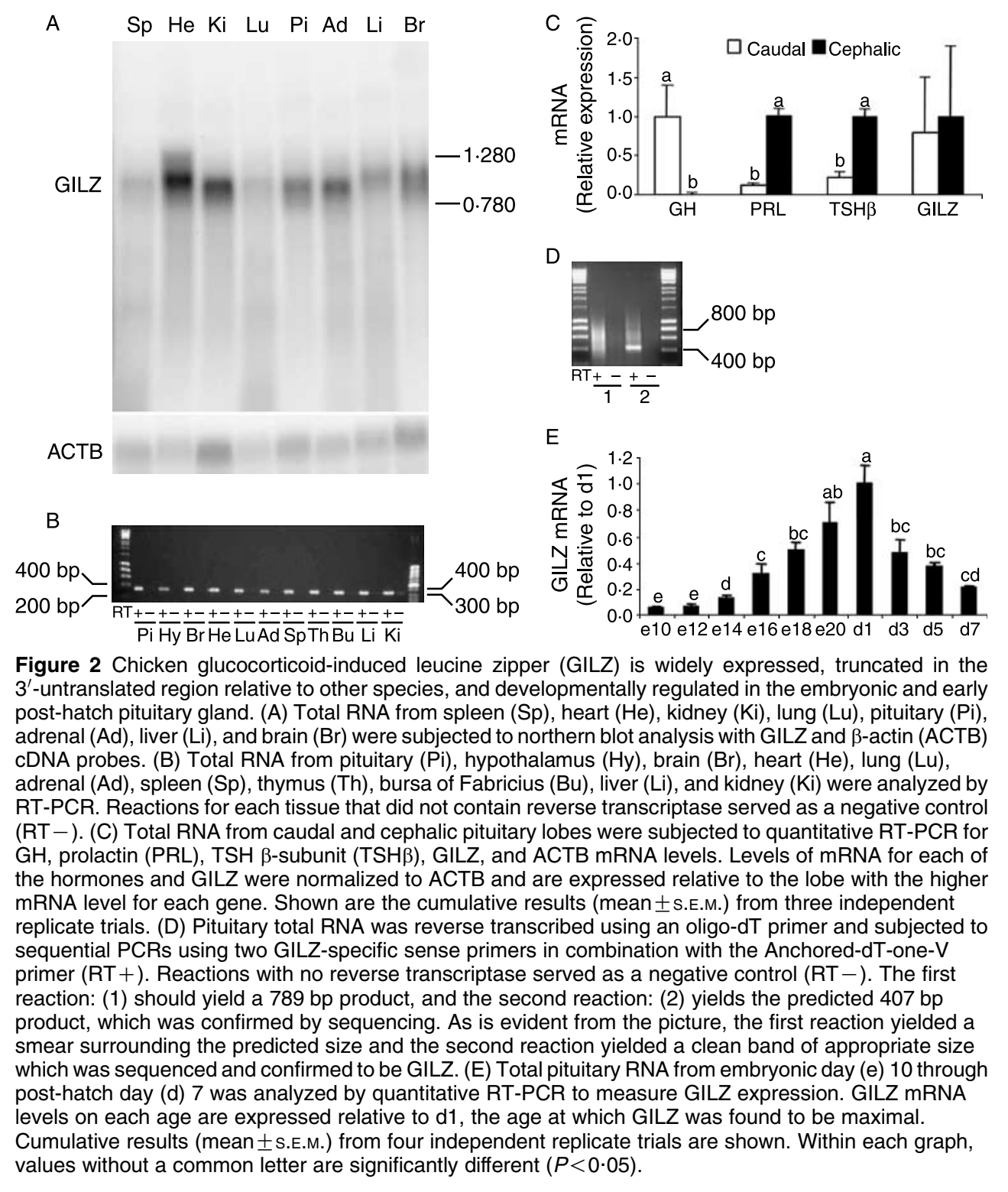

that there are differences in the regulation of GILZ expression at the post-transcriptional level between mammals and birds.

\section{Chicken GILZ is ubiquitously expressed}

Both northern blot and RT-PCR analyses were used to determine the tissue distribution of GILZ in the chicken. In both methods, GILZ was detected in all tissues examined (Fig. 2A and B), namely pituitary, hypothalamus, brain, heart, lung, adrenal, spleen, thymus, bursa of Fabricius, liver, and kidney. Given that GILZ is present in the pituitary, we sought to further define localization within this tissue because the avian anterior pituitary consists of two anatomically distinct caudal and cephalic lobes. In the chicken, four of the major pituitary cell types are unevenly distributed among these two lobes. GH-producing somatotrophs reside primarily in the caudal lobe, while PRLproducing lactotrophs, TSH-producing thyrotrophs, and ACTH-producing corticotrophs are mainly localized within the cephalic lobe (Kansaku et al. 1995, Lopez et al. 1995, Gerets et al. 2000, Nakamura et al. 2004, Muchow et al. 2005). Gonadotrophs, which produce $\mathrm{LH}$ and $\mathrm{FSH}$, are initially present in the caudal lobe but spread throughout the entire gland as the pituitary develops (Maseki et al. 2004). We measured mRNA levels of GH, PRL, TSH $\beta$, and GILZ in caudal 
Table 2 Chicken glucocorticoid-induced leucine zipper (GILZ) sequence was compared with those of human, mouse, dog, zebrafish, and Xenopus GILZ

Percentage of identical nucleic acids ${ }^{a}$

Entire sequence $^{\mathrm{b}} \quad$ Coding region ${ }^{\mathrm{c}}$

Species

Human $^{\text {d }}$

Mouse $^{d}$

Dog ${ }^{\mathrm{e}}$

Zebrafish

Xenopus $^{\mathrm{d}}$

\begin{tabular}{ll}
$59 \cdot 3$ & $80 \cdot 0$ \\
$57 \cdot 4$ & $80 \cdot 5$ \\
$57 \cdot 7$ & $79 \cdot 3$ \\
$56 \cdot 0$ & $75 \cdot 3$ \\
$57 \cdot 1$ & $74 \cdot 8$ \\
\hline
\end{tabular}

Percentage of homologous amino acids (AAs) ${ }^{a}$

Identical AAs Positive substitutions

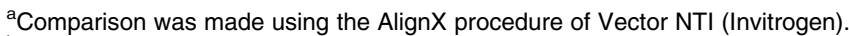

${ }^{\mathrm{b}}$ Comparison was made over the length of $1118 \mathrm{bps}$.

'Comparison was made between the start codon (ATG) and stop codon (TAA) for each species.

dHuman (accession numbers NM 004089 and NP 004080), Mouse (accession numbers NM 010286 and NP 034416), and Xenopus (accession numbers BC043841 and $\mathrm{AAH} 43841)$ sequences are cloned mRNAs.

eDog (accession numbers XM_549177 and XP_549177) and Zebrafish (accession numbers XM_703382 and XP_708474) are predicted transcripts derived from computational analysis.

and cephalic portions of the pituitary glands from chicks just prior to hatch. It should be noted that the higher variation in GILZ mRNA relative to that for the pituitary hormones measured is not due to normalization and appears to reflect true biological variability in the samples collected. Regardless, results from qRTPCR analysis indicate that GILZ mRNA is equivalently expressed in both lobes in a manner similar to LH and FSH, and confirm the caudal distribution of GH mRNA and cephalic localization of PRL and TSH $\beta$ mRNA $(P<0 \cdot 05 ; n=3$; Fig. 2C).

\section{GILZ is developmentally regulated in the pituitary gland}

The mature anterior pituitary gland consists of five major cell types that emerge during development in a temporally specific manner. Initiation of hormone transcription in these cells occurs during the second half of embryogenesis and continues during early neonatal life in both mammals and birds (Japon et al. 1994, Sasaki et al. 2003, Ellestad et al. 2006). Pituitary $\alpha \mathrm{GSU}, \mathrm{POMC}$, and TSH $\beta$ mRNAs steadily increase during the second half of embryogenesis, expression of GH, PRL, and FSH $\beta$ mRNA increases most substantially during the last third of embryogenesis, and LH $\beta$ mRNA is not abundant until after hatch (Ellestad et al. 2006, Ellestad and Porter, unpublished). We characterized pituitary GILZ mRNA during this time in order to determine whether GILZ is regulated in a manner consistent with a potential role in pituitary development. GILZ mRNA was measured during the latter half of chicken embryonic development and the first week post-hatch, from e10 through d7. Expression increased between e12 and e14 and continued to dramatically increase during the final third of embryonic development to a maximum immediately post-hatch, and then decreased through d7 $(P<0 \cdot 05 ; n=4 ;$ Fig. $2 \mathrm{E})$. The expression profile measured in this experiment indicates that GILZ may play a developmental role in this tissue, and it is most consistent with a putative role in the development of gonadotrophs, somatotrophs, and lactotrophs based on timing of their appearance.

\section{GILZ is upregulated by glucocorticoids in chicken embryonic pituitary cells}

The expression profile of GILZ in the developing chicken pituitary gland is consistent with upregulation by glucocorticoids, because circulating CORT increases in a similar manner to GILZ during embryogenesis (Jenkins et al. 2007, Porter et al. 2007). To determine whether glucocorticoids can induce GILZ in embryonic pituitary cells from birds at an age when circulating CORT is comparably low, we analyzed GILZ mRNA in e11 pituitary cells treated with CORT $(1 \mathrm{nM})$ by qRT-PCR. This dose of CORT was chosen because it reflects circulating levels of CORT on e14, the embryonic age at which GILZ expression first begins to increase in the chicken (Jenkins et al. 2007, Porter et al. 2007). CORT treatment induced GILZ mRNA after 3 and $6 \mathrm{~h}$, and there was a further increase after $12 \mathrm{~h}(P<0 \cdot 05 ; n=4$; Fig. 3A). In an attempt to evaluate whether GILZ is a direct transcriptional target of CORT, we cultured e11 anterior pituitary cells for $1 \cdot 5,3$, and $6 \mathrm{~h}$ with CORT in the presence of CHX, an inhibitor of protein synthesis (Fig. 3B). Similar to the results shown in Fig. 3A, GILZ was upregulated almost threefold after $1.5 \mathrm{~h}$ CORT treatment, and this upregulation was maintained through $6 \mathrm{~h}(P<0 \cdot 05 ; n=4)$. However, because treatment with CHX alone for $1.5 \mathrm{~h}$ stimulated GILZ mRNA in these cells to a level similar to that with CORT alone for $1.5 \mathrm{~h}(P<0.05 ; n=4$; Fig. 3C, compare white and black bars at $0 \mathrm{~h}$ and black bar at $0 \mathrm{~h}$ with white bar at $1.5 \mathrm{~h}$ ), it 

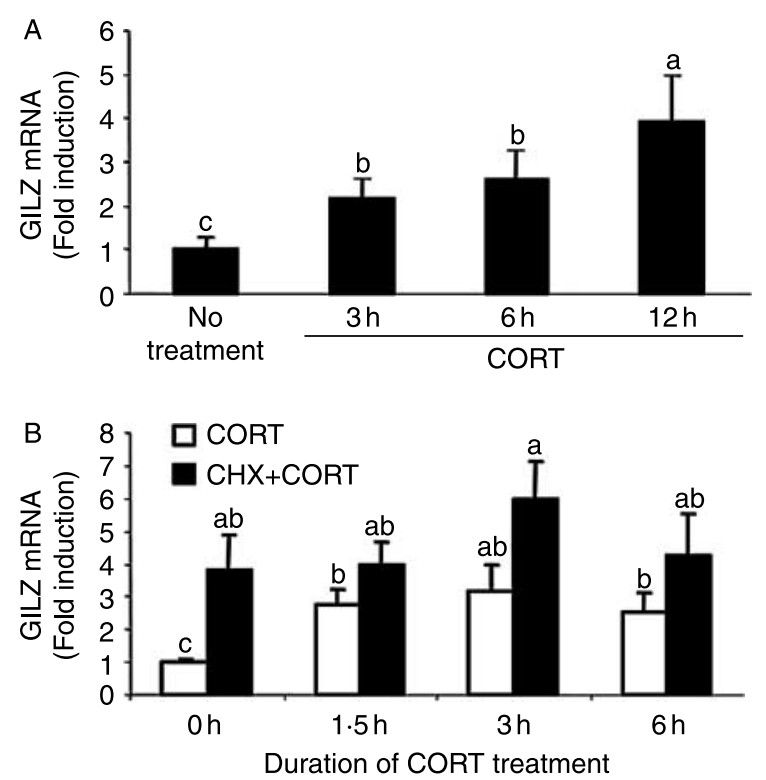

Figure 3 Corticosterone (CORT) rapidly induces expression of glucocorticoid-induced leucine zipper (GILZ) in cultured chicken embryonic anterior pituitary cells. (A) Total RNA extracted from embryonic day (e) 11 anterior pituitary cells cultured for $24 \mathrm{~h}$ and treated with CORT ( $1 \mathrm{nM}$ ) for the final 3,6 , or $12 \mathrm{~h}$ of culture were analyzed by quantitative RT-PCR for GILZ and $\beta$-actin (ACTB) mRNA. GILZ mRNA levels were normalized to ACTB and are expressed relative to GILZ mRNA in control cells. Shown are the cumulative results (mean \pm s.E.M.) from four independent replicate trials. (B) Total RNA extracted from e11 anterior pituitary cells treated with CORT in the absence (CORT) and presence of $\mathrm{CHX}$ $(\mathrm{CHX}+\mathrm{CORT})$ for the final $0,1 \cdot 5,3$, and $6 \mathrm{~h}$ of a $24 \mathrm{~h}$ culture were analyzed by quantitative RT-PCR for GILZ and ACTB mRNA. The $0 \mathrm{~h}$ time point reflects cells receiving no treatment (white bar) or cells receiving $\mathrm{CHX}$ alone (black bar) for $1.5 \mathrm{~h}$. GILZ mRNA levels were normalized to ACTB and are expressed relative to GILZ mRNA in control cells (receiving no CORT and no CHX). Cumulative results (mean \pm s.E.M.) are from four independent replicate trials. Within each graph, values without a common letter are significantly different $(P<0 \cdot 05)$.

cannot be determined from the current experiments whether GILZ is a direct transcriptional target of glucocorticoids in these cells. Nonetheless, treatment with CORT does lead to a rapid upregulation of GILZ mRNA expression in embryonic anterior pituitary cells.

\section{Overexpression of GILZ alters hormone gene expression in the developing pituitary gland}

Pituitary GILZ is developmentally regulated and may be directly induced by CORT. Therefore, we sought to determine whether overexpression of GILZ in embryonic pituitary cells may influence mRNA levels for the pituitary hormones that transcription is initiated during mid- to late embryogenesis. These include GH, PRL, and POMC, which are known to be regulated by glucocorticoids (Hemming et al. 1984, Drouin et al.
1989, Nogami et al. 1995, Morpurgo et al. 1997, Dean \& Porter 1999, Dean et al. 1999, Bossis \& Porter 2003, Fu \& Porter 2004), as wells as $\alpha \mathrm{GSU}$, TSH $\beta, \mathrm{LH} \beta$, and FSH $\beta$. Pituitary hormone mRNAs are expressed at relatively low levels during mid-embryonic development and increase after e10 (Ellestad et al. 2006 and unpublished observations). As has been reported previously (Ellestad et al. 2006), we found that endogenous GILZ expression began to increase after e14 (Fig. 2E) but is induced by CORT on earlier embryonic ages when anterior pituitary cells are exposed to CORT $(1 \mathrm{nM})$ at a concentration similar to that found in circulation on e14 (Fig. 3). In order to evaluate whether GILZ plays a role in the initiation of anterior pituitary hormone expression, we investigated effects of GILZ overexpression in mid-embryonic development, when pituitary hormone mRNA levels are relatively low. Anterior pituitary cells from e11 embryos $(n=4$ replicate experiments) were transfected with an expression vector containing GILZ driven by the cytomegalovirus (CMV) promoter or empty vector (Sport6.1) along with a golgi-targeted GFP expression vector, used for sorting of successfully transfected (GFP-positive) cells. We then analyzed GILZ mRNA and mRNA for each of the pituitary hormones to determine which of the genes were regulated by CORT on e11 and which of the hormones were potentially regulated by GILZ.

We first measured mRNA for pituitary genes that are known to be regulated by CORT (Fig. 4). Similar to the results shown above (Fig. 3) and as previously demonstrated (Hemming et al. 1984, Nogami et al. 1995, Morpurgo et al. 1997, Dean \& Porter 1999, Dean et al. 1999, Bossis \& Porter 2003, Fu \& Porter 2004), CORT treatment induced GILZ (3.5-fold), GH $(12 \cdot 5$ fold), and PRL (3.5-fold) $(P<0 \cdot 05)$. However, CORT did not affect POMC expression. These results also demonstrate that the CMV promoter was able to substantially drive expression of GILZ in these cells $(P<0 \cdot 05)$. Overexpression of GILZ had no effect on GH mRNA in the absence or presence of CORT, but cells transfected with GILZ in the absence of CORT had intermediate levels of PRL mRNA when compared with basal cells transfected with empty vector and cells treated with CORT $(P<0 \cdot 05)$. Similarly, cells transfected with GILZ in the absence of CORT had significantly, although modestly, higher POMC mRNA than basal cells transfected with empty vector $(P<0 \cdot 05)$, but this effect was not apparent in the presence of CORT. This indicates that CORT may be inducing factors that prevent the slight upregulation of POMC by GILZ. Together, these results imply that GILZ may play a minor role in the induction of PRL by glucocorticoids during pituitary development and that GILZ can upregulate POMC mRNA in embryonic pituitary cells in the absence of glucocorticoids. 

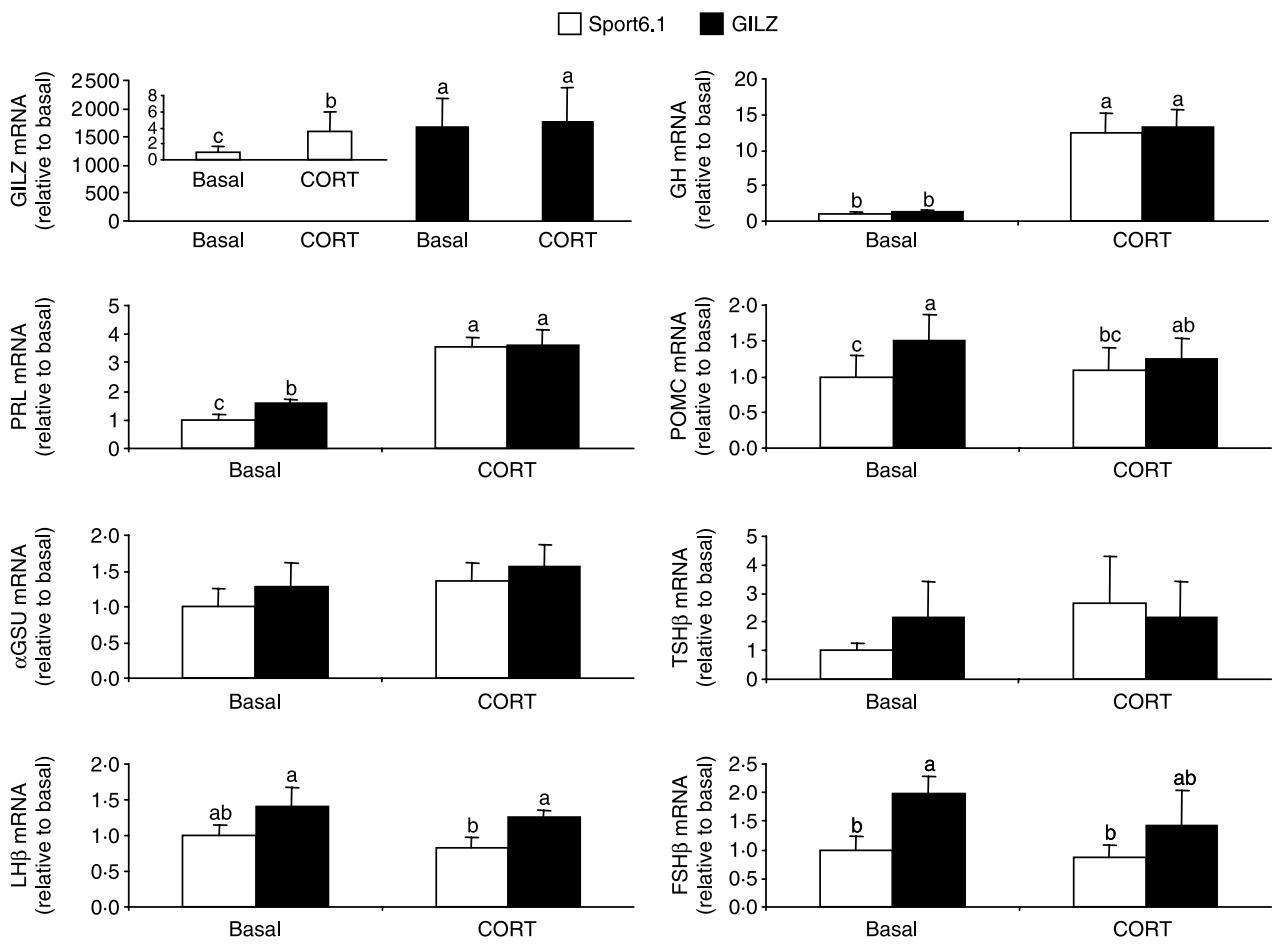

Figure 4 Expression of glucocorticoid-induced leucine zipper (GILZ) in chick embryonic anterior pituitary cells modestly increases levels of prolactin (PRL), pro-opiomelanocortin (POMC), and FSH $\beta$-subunit $(\mathrm{FSH} \beta)$ mRNA. Embryonic day (e) 11 anterior pituitary cells were transiently transfected with a green fluorescent protein (GFP) expression vector and an expression vector for GILZ or empty vector (Sport6.1) and left untreated (Basal) or treated with corticosterone (CORT; $1 \mathrm{nM}$ ) for the last $15 \mathrm{~h}$ of culture. After flow cytometric cell sorting, total RNA from GFP-positive cells was extracted, amplified, and analyzed by quantitative RT-PCR for GILZ, GH, PRL, POMC, $\alpha$-glycoprotein hormone subunit ( $\alpha \mathrm{GSU})$, TSH $\beta$-subunit (TSH $\beta$ ), LH $\beta$-subunit (LH $\beta$ ), FSH $\beta$, and $\beta$-actin (ACTB) mRNA. All mRNA levels were normalized to ACTB and are expressed relative to levels in Basal cells transfected with Sport6.1. Inset in GILZ graph depicts the level of GILZ mRNA in cells transfected with Sport6.1 treated with and without CORT. Shown are results (mean \pm S.E.M.) of four independent replicate trials. Within each graph, values without a common letter are significantly different $(P<0 \cdot 05)$.

We also measured mRNA levels for $\alpha \mathrm{GSU}, \mathrm{TSH} \beta$, LH $\beta$, and FSH $\beta$, which have not been shown to be regulated by corticosteroids during pituitary development, to determine whether GILZ might regulate glycoprotein hormone expression (Fig. 4). Neither GILZ overexpression nor CORT affected levels of $\alpha \mathrm{GSU}$ or TSH $\beta$ in el1 cells. Expression of GILZ increased FSH $\beta$ and LH $\beta$ mRNA under basal and CORT-treated conditions respectively $(P<0 \cdot 05)$, although CORT itself had no effect. These results indicate that GILZ may positively regulate expression of pituitary gonadotropins, and they suggest that GILZ may have effects on gene expression that are independent from its regulation by glucocorticoids.

\section{Discussion}

This is the first report to characterize GILZ in an avian species, and the first to investigate expression, regulation, and a potential function for GILZ in neuroendocrine development. We sequenced a chicken GILZ cDNA clone, and it contained an insert that was only $1118 \mathrm{bp}$ long, $\sim 650 \mathrm{bp}$ shorter than GILZ in other vertebrates. The insert contained the entire predicted open reading frame for GILZ, and the majority of the truncation (500 bp) lies within the 3 -untranslated region and the remainder within the $5^{\prime}$-untranslated region. The estimated transcript size for chicken GILZ was confirmed by northern blotting in all tissues and the $3^{\prime}$-end of the transcript was verified using $3^{\prime}$-RACE, indicating that this is the predominant form of GILZ in chickens. This truncation may imply an alternative regulation of GILZ mRNA at the posttranscriptional level in birds, as elements within the 3'-untranslated region are thought to modulate mRNA stability (Hughes 2006). Despite this truncation, the coding region of GILZ mRNA and the predicted protein are highly homologous with those from other species, including the conserved leucine zipper region 
facilitating protein-protein interactions (homo- or heterodimerization) that regulate DNA-binding characteristics of this family of transcription factors.

In the chicken, GILZ mRNA was detected in every tissue we examined, including the pituitary. In mammals, GILZ has been shown to be expressed in a variety of tissues and cell types, including heart, brain, kidney, liver, lung, pancreas, spleen, muscle, uterus, mesenchymal cells, pre-adipocytes, and white and red blood cells (Cannarile et al. 2001, Berrebi et al. 2003, Kolbus et al. 2003, Shi et al. 2003, Zhao et al. 2006). However, this is the first report indicating expression of GILZ in the neuroendocrine system of any species. Within the pituitary, GILZ was detected in both caudal and cephalic lobes, indicating that GILZ expression is not restricted to any particular cell type or is present in cell types that are distributed throughout the avian gland, such as gonadotrophs (Maseki et al. 2004).

In the developing chicken embryo, circulating glucocorticoids increase from subnanomolar concentrations on e12 to $1-5 \mathrm{nM}$ on e14, and increase further to $40-50 \mathrm{nM}$ on e17 before decreasing slightly on e20 (Scott $e t$ al. 1981, Jenkins $e t$ al. 2007, Porter et al. 2007). After hatch, circulating glucocorticoids remain in the $10-30 \mathrm{nM}$ range during the first week of neonatal life, with serum levels peaking on $\mathrm{d} 1$, and declining through $\mathrm{d} 4$ before rising again on $\mathrm{d} 5$ (Latour et al. 1995). The developmental profile of pituitary GILZ mRNA during the second half of embryonic and early post-hatch development measured in the current study reflect these levels of serum CORT and are consistent with an in vivo regulation of GILZ by circulating glucocorticoids. We found that GILZ expression increased slightly between e12 and e14, then dramatically increased through d1, after which mRNA levels decreased through the remainder of the experiment. These data are consistent with our previous report, where GILZ mRNA was shown to increase between e 12 and e 17 by both microarray and qRT-PCR analysis (Ellestad et al. 2006). This potential upregulation of GILZ by CORT in the chicken pituitary was confirmed by in vitro experiments, in which cultured e11 pituitary cells treated with CORT at a level similar to that found in the e14 embryo had significantly higher levels of GILZ mRNA than those left untreated.

In cultured chick embryonic pituitary cells, GILZ mRNA was upregulated by CORT within $1.5 \mathrm{~h}$. The magnitude of induction observed in these cells, between two- and fourfold, is consistent with induction of the mammalian GILZ transcript by the synthetic glucocorticoid dexamethasone in non-lymphoid tissues (Kolbus et al. 2003, Chen et al. 2006). In lymphoid cells, however, glucocorticoids appear to induce GILZ gene expression more strongly (D'Adamio et al. 1997, Cannarile et al. 2001, Asselin-Labat et al. 2005). One mode of action of glucocorticoids is to bind the intracellular glucocorticoid receptor (GR), which then acts as a ligand-activated transcription factor that binds to glucocorticoid response elements (GREs) in the regulatory regions of direct target genes. In the developing chick anterior pituitary, GR mRNA and protein are present by $\mathrm{e} 8$ and both increase in expression during embryonic development (Bossis et al. 2004, Ellestad et al. 2006, Kwok et al. 2007). GR protein is found in almost all chicken anterior pituitary cells (Bossis et al. 2004) indicating that GILZ may be a direct transcriptional target of GR in these cells. In mammalian cells, GILZ mRNA is increased in as little as $15 \mathrm{~min}$ after exposure to dexamethasone and is induced even in the presence of a protein synthesis inhibitor (Asselin-Labat et al. 2005, Chen et al. 2006) further supporting that GILZ is likely a direct glucocorticoid transcriptional target. This is consistent with the presence of multiple GREs in the human GILZ promoter (Asselin-Labat et al. 2005). However, because it was induced by CHX in chicken embryonic pituitary cells, it is impossible to determine from the current experiments if GILZ is indeed a direct transcriptional target in the developing pituitary gland. Further, the GILZ gene falls within an unassembled region of the chicken genome, so in silico promoter analysis for GREs in this species has not yet been possible. Nonetheless, our present findings indicate that GILZ is rapidly upregulated by CORT in the developing pituitary gland.

During development, glucocorticoids play a role in functional maturation of several tissues, including lung (Cole et al. 2004), small intestine (Thomson \& Keelan 1986), and pituitary (Nogami et al. 1995, Dean \& Porter 1999, Fu \& Porter 2004). In mammals and birds, glucocorticoids stimulate GH and PRL expression during somatotroph and lactotroph differentiation respectively, in the course of anterior pituitary development (Hemming et al. 1984, Nogami et al. 1995, Morpurgo et al. 1997, Dean \& Porter 1999, Dean et al. 1999, Bossis \& Porter 2003, Fu \& Porter 2004). The timing of this stimulation and, in the case of $\mathrm{GH}$, requirement for ongoing protein synthesis, implicates an indirect mechanism requiring induction of an intermediary protein (Nogami et al. 1997, Porter et al. 2001, Bossis \& Porter 2003). Glucocorticoids are also known to repress POMC expression during negative feedback on ACTH release from corticotrophs (Drouin et al. 1989), although the time during hypothalamicpituitary-adrenal axis ontogeny when this feedback is first established is unknown. Pituitary GILZ shows developmental regulation consistent with the increase in circulating glucocorticoids that occurs during the second half of embryonic development, and GILZ is upregulated by CORT in embryonic pituitary cells. These observations led us to hypothesize that GILZ may play a role in mediating levels of the pituitary hormones, expression of which is initiated by corticosteroids during 
development. In addition, GILZ is present in the embryonic pituitary gland at the earliest age we investigated, e10, even when circulating CORT levels are low, and GILZ may play a role in initiating expression of hormones that are not induced by glucocorticoids.

GILZ overexpression in embryonic pituitary cells did not affect GH mRNA, either in the presence or absence of CORT, indicating it is not involved in somatotroph development. On the other hand, GILZ overexpression did modestly increase PRL to $165 \%$ and POMC to $150 \%$ of mRNA levels in the absence of CORT. In the case of PRL, GILZ overexpression increased PRL mRNA to a level intermediate between basal cells and those receiving CORT. This indicates that, while GILZ alone is capable of positively regulating PRL expression in embryonic pituitary cells, it likely plays a minor role in the induction of PRL by CORT and the regulation of other factors by glucocorticoids is also required. The increase of POMC expression in the presence of exogenous GILZ, although slight, may contribute to the lack of a negative effect of CORT on POMC mRNA in these experiments. At this embryonic age, GILZ that is induced by CORT may positively regulate POMC mRNA in a manner that prevents its downregulation by glucocorticoids. Overexpression of GILZ also upregulated levels of LH $\beta$ and FSH $\beta$. The twofold increase in FSH $\beta$ mRNA in the absence of CORT was the greatest effect we observed in these experiments, although this effect was diminished in the presence of CORT. While cortisol does repress the reproductive axis in mammals (Breen \& Karsch 2004, Gore et al. 2006), these genes have not previously been shown to be developmentally regulated by glucocorticoids. Consistent with this, CORT did not affect levels of gonadotropin $\beta$-subunit mRNA in chicken embryonic pituitary cells. This indicates that any positive regulation GILZ may have on gonadotropin $\beta$-subunit mRNA levels during embryogenesis is independent of their regulation by glucocorticoids. The distribution of GILZ in the avian pituitary, the ontogenic profile of $\mathrm{FSH} \beta$ during embryonic development (Ellestad and Porter, unpublished), and the increase in FSH $\beta$ mRNA in the presence of exogenous GILZ are all consistent with a role for this gene in pituitary gonadotroph development. It should be noted that a role for GILZ in regulation of the pituitary hormones at later embryonic stages, or even post-hatch, cannot be ruled out by the current experiments.

In conclusion, this is the first report in which an avian GILZ homolog has been characterized and the first demonstration that GILZ is present and regulated by glucocorticoids in the anterior pituitary gland of any species. Due to the spatial and temporal conservation of pituitary gland development among vertebrates, the results presented should be relevant in mammalian systems. We have elucidated GILZ mRNA expression profiles during both embryonic and neonatal development. The expression profile is consistent with a potential role in initiation of hormone transcription during embryogenesis, particularly for those hormones that are known to be positively regulated by corticosteroids during development, namely GH and PRL. GILZ does not appear to play a role in somatotroph development, but may contribute to lactotroph development by playing a minor role in initiation of PRL expression in combination with other factors regulated by glucocorticoids. Finally, GILZ may also contribute to gonadotroph development by positively regulating gonadotropin $\beta$-subunit mRNA, primarily that of FSH $\beta$, during embryogenesis.

\section{Declaration of interest}

The authors declare that there is no conflict of interest that would prejudice the impartiality of this scientific work.

\section{Funding}

This project was supported by National Research Initiative Competitive Grant no. 2003-35206-12836 from the USDA Cooperative State Research, Education, and Extension Service.

\section{References}

Asselin-Labat M-L, Biola-Vidamment A, Kerbrat S, Lombes M, Bertoglio J \& Pallardy M 2005 FoxO3 mediates antagonistic effects of glucocorticoids and interleukin-2 on glucocorticoid-induced leucine zipper expression. Molecular Endocrinology 19 1752-1764.

Ayroldi E, Migliorati G, Bruscoli S, Marchetti C, Zollo O, Cannarile L, D'Adamio F \& Riccardi C 2001 Modulation of T-cell activation by the glucocorticoid-induced leucine zipper factor via inhibition of nuclear factor KB. Blood 98 743-753.

Ayroldi E, Zollo O, Macchiarulo A, Di Marco B, Marchetti C \& Riccardi C 2002 Glucocorticoid-induced leucine zipper inhibits the Rafextracellular signal-regulated kinase pathway by binding to Raf-1. Molecular and Cellular Biology 22 7929-7941.

Ayroldi E, Zollo O, Bastianelli A, Marchetti C, Agostini M, Di Virgilio R \& Riccardi C 2007 GILZ Mediates the antiproliferative activity of glucocorticoids by negative regulation of Ras signaling. Journal of Clinical Investigation 117 1605-1615.

Berrebi D, Bruscoli S, Cohen N, Foussat A, Migliorati G, Bouchet-Delbos L, Maillot M-C, Portier A, Couderc J, Galanaud P et al. 2003 Synthesis of glucocorticoid-induced leucine zipper (GILZ) by macrophages: an anti-inflammatory and immunosuppressive mechanism shared by glucocorticoids and IL-10. Blood 101 729-738.

Bossis I \& Porter TE 2000 Ontogeny of corticosterone-inducible growth hormone-secreting cells during chick embryonic development. Endocrinology 141 2683-2690.

Bossis I \& Porter TE 2003 Evaluation of glucocorticoid-induced growth hormone gene expression in chicken embryonic pituitary cells using a novel in situ mRNA quantitation method. Molecular and Cellular Endocrinology 201 13-23.

Bossis I, Nishimura S, Muchow M \& Porter TE 2004 Pituitary expression of type I and type II glucocorticoid receptors during chicken embryonic development and their involvement in growth hormone cell differentiation. Endocrinology 145 3523-3531.

Breen KM \& Karsch FJ 2004 Does cortisol inhibit pulsatile luteinizing hormone secretion at the hypothalamic or pituitary level? Endocrinology 145 692-698. 
Bruscoli S, Di Virgilio R, Donato V, Velardi E, Baldoni M, Marchetti C, Migliorati G \& Riccardi C 2006 Genomic and non-genomic effects of different glucocorticoids on mouse thymocyte apoptosis. European Journal of Pharmacology 529 63-70.

Cannarile L, Zollo O, D'Adamio F, Ayroldi E, Marchetti C, Tabilio A, Bruscoli S \& Riccardi C 2001 Cloning, chromosomal assignment and tissue distribution of human GILZ, a glucocorticoid hormoneinduced gene. Cell Death and Differentiation 8 201-203.

Carre W, Wang X, Porter TE, Nys Y, Tang J, Bernberg E, Morgan R, Burnside J, Aggrey SE, Simon J et al. 2006 Chicken genomics resource: sequencing and annotation of 35407 ESTs from single and multiple tissue cDNA libraries and CAP3 assembly of a chicken gene index. Physiological Genomics 25 514-524.

Chen W, Rogatsky I \& Garabedian MJ 2006 MED14 and MED1 differentially regulate target-specific gene activation by the glucocorticoid receptor. Molecular Endocrinology 20 560-572.

Cogburn LA, Wang X, Carre W, Rejto L, Aggrey SE, Duclos MJ, Simon J \& Porter TE 2004 Functional genomics in chickens: development of integrated-systems microarrays for transcriptional profiling and discovery of regulatory pathways. Comparative and Functional Genomics 5 253-261.

Cole TJ, Solomon NM, Driel RV, Monk JA, Bird D, Richardson SJ, Dilley RJ \& Hooper SB 2004 Altered epithelial cell proportions in the fetal lung of glucocorticoid receptor null mice. American Journal of Respiratory Cell and Molecular Biology 30 613-619.

D'Adamio F, Zollo O, Moraca R, Ayroldi E, Bruscoli S, Bartoli A, Cannarile L, Migliorati G \& Riccardi C 1997 A new dexamethasoneinduced gene of the leucine zipper family protects $\mathrm{T}$ lymphocytes from TCR/CD3-activated cell death. Immunity 7 803-812.

Dean CE \& Porter TE 1999 Regulation of somatotroph differentiation and growth hormone (GH) secretion by corticosterone and GH-releasing hormone during embryonic development. Endocrinology 140 1104-1110.

Dean CE, Morpurgo B \& Porter TE 1999 Induction of somatotroph differentiation in vivo by corticosterone administration during chicken embryonic development. Endocrine 11 151-156.

Drouin J, Nemer M, Charron J, Gagner JP, Jeannotte L, Sun YL, Therrien M \& Tremblay Y 1989 Tissue-specific activity of the proopiomelanocortin (POMC) gene and repression by glucocorticoids. Genome 31 510-519.

Ellestad LE, Carre W, Muchow M, Jenkins SA, Wang X, Cogburn LA \& Porter TE 2006 Gene expression profiling during cellular differentiation in the embryonic pituitary gland using cDNA microarrays. Physiological Genomics 25 414-425.

Fu X \& Porter TE 2004 Glucocorticoid induction of lactotrophs and prolactin gene expression in chicken embryonic pituitary cells: a delayed response relative to stimulated growth hormone production. Endocrinology 145 1322-1330.

Gerets HHJ, Peeters K, Arckens L, Vandesande F \& Berghman LR 2000 Sequence and distribution of pro-opiomelanocortin in the pituitary and brain of the chicken. Journal of Comparative Neurology 417 250-262.

Gore AC, Attardi B \& DeFranco DB 2006 Glucocorticoid repression of the reproductive axis: effects on $\mathrm{GnRH}$ and gonadotropin subunit mRNA levels. Molecular and Cellular Endocrinology 256 40-48.

Hemming FJ, Begeot M, Dubois MP \& Dubois PM 1984 Fetal rat somatotropes in vitro: effects of insulin, cortisol, and growth hormone-releasing factor on their differentiation: a light and electron microscopic study. Endocrinology 114 2107-2113.

Hughes TA 2006 Regulation of gene expression by alternative untranslated regions. Trends in Genetics 22 119-122.

Japon MA, Rubinstein M \& Low MJ 1994 In situ hybridization analysis of anterior pituitary hormone gene expression during fetal mouse development. Journal of Histochemistry and Cytochemistry 42 1117-1125.

Jenkins SA, Muchow M, Richards MP, McMurtry JP \& Porter TE 2007 Administration of adrenocorticotropic hormone during chicken embryonic development prematurely induces pituitary growth hormone cells. Endocrinology 148 3914-3921.
Kansaku N, Shimada K \& Saito N 1995 Regionalized gene expression of prolactin and growth hormone in the chicken anterior pituitary gland. General and Comparative Endocrinology 99 $60-68$.

Kolbus A, Blazquez-Domingo M, Carotta S, Bakker W, Luedemann S, vonLindern M, Steinlein P \& Beug H 2003 Cooperative signaling between cytokine receptors and the glucocorticoid receptor in the expansion of erythroid progenitors: molecular analysis by expression profiling. Blood 102 3136-3146.

Kwok AHY, Wang Y, Wang CY \& Leung FC 2007 Cloning of chicken glucocorticoid receptor (GR) and characterization of its expression in pituitary and extrapituitary tissues. Poultry Science $\mathbf{8 6}$ 423-430.

Latour MA, Peebles ED, Boyle CR, Brake JD \& Kellogg TF 1995 Changes in serum lipid, lipoprotein and corticosterone concentrations during neonatal chick development. Biology of the Neonate 67 381-386.

Levine B, Jean-Francois M, Bernardi F, Gargiulo G \& Dobens L 2007 Notch signaling links interactions between the C/EBP homolog slow border cells and the GILZ homolog bunched during cell migration. Developmental Biology 305 217-231.

Lopez ME, Hargis BM, Dean CE \& Porter TE 1995 Uneven regional distributions of prolactin-and growth hormone-secreting cells and sexually dimorphic proportions of prolactin secretors in the adenohypophysis of adult chickens. General and Comparative Endocrinology 100 246-254.

Maseki Y, Nakamura K, Iwasawa A, Zheng J, Inoue K \& Sakai T 2004 Development of gonadotropes in the chicken embryonic pituitary gland. Zoological Science 21 435-444.

Mittelstadt PR \& Ashwell JD 2001 Inhibition of AP-1 by the glucocorticoid-inducible protein GILZ. Journal of Biological Chemistry 276 29603-29610.

Morpurgo B, Dean CE \& Porter TE 1997 Identification of the blood-borne somatotroph-differentiating factor during chicken embryonic development. Endocrinology 138 4530-4535.

Muchow M, Bossis I \& Porter TE 2005 Ontogeny of pituitary thyrotrophs and regulation by endogenous thyroid hormone feedback in the chick embryo. Journal of Endocrinology 184 407-416.

Nakamura K, Iwasawa A, Kidokoro H, Komoda M, Zheng J, Maseki Y, Inoue K \& Sakai T 2004 Development of thyroid-stimulating hormone beta subunit-producing cells in the chicken embryonic pituitary gland. Cells, Tissues, Organs 177 21-28.

Nogami H, Yokose T \& Tachibana T 1995 Regulation of growth hormone expression in fetal rat pituitary gland by thyroid or glucocorticoid hormone. American Journal of Physiology 268 E262-E267.

Nogami H, Inoue K \& Kawamura K 1997 Involvement of glucocorticoid-induced factor(s) in the stimulation of growth hormone expression in the fetal rat pituitary gland in vitro. Endocrinology 138 $1810-1815$.

Pecot MY \& Malhotra V 2004 Golgi membranes remain segregated from the endoplasmic reticulum during mitosis in mammalian cells. Cell 116 99-107.

Phillips J \& Eberwine JH 1996 Antisense RNA amplification: a linear amplification method for analyzing the mRNA population from single living cells. Methods 10 283-288.

Porter TE \& Ellestad LE 2005 Gene expression profiling in the developing neuroendocrine system of the chick. In Functional Avian Endocrinology, pp 45-56. Eds A Dawson \& PJ Sharp. New Delhi: Narosa Publishing House.

Porter TE, Couger GS, Dean CE \& Hargis BM 1995 Ontogeny of growth hormone $(\mathrm{GH})$-secreting cells during chicken embryonic development: initial somatotrophs are responsive to GH-releasing hormone. Endocrinology 136 1850-1856.

Porter TE, Dean CE, Piper MM, Medvedev KL, Ghavam S \& Sandor J 2001 Somatotroph recruitment by glucocorticoids involves induction of growth hormone gene expression and secretagogue responsiveness. Journal of Endocrinology 169 499-509. 
Porter TE, Ghavam S, Muchow M, Bossis I \& Ellestad L 2007 Cloning of partial cDNAs for the chicken glucocorticoid and mineralocorticoid receptors and characterization of mRNA levels in the anterior pituitary gland during chick embryonic development. Domestic Animal Endocrinology 33 226-239.

Sambrook J, Fritsch EF \& Maniatis T 1989. Molecular Cloning: A Laboratory Manual, 2. Cold Spring Harbor, NY: Cold Spring Harbor Press.

Sasaki F, Doshita A, Matsumoto Y, Kuwahara S, Tsukamoto Y \& Agawa K 2003 Embryonic development of the pituitary gland in the chick. Cells, Tissues, Organs 173 65-74.

Scott TR, Johnson WA, Satterlee DG \& Gildersleeve RP 1981 Circulating levels of corticosterone in the serum of developing chick embryos and newly hatched chicks. Poultry Science 60 1314-1320.

Shi X, Shi W, Li Q, Song B, Wan M, Bai S \& Cao X 2003 A glucocorticoid-induced leucine-zipper protein, GILZ, inhibits adipogenesis of mesenchymal cells. EMBO Reports 4 374-380.
Soundararajan R, Zhang TT, Wang J, Vandewalle A \& Pearce D 2005 A novel role for glucocorticoid-induced leucine zipper protein in epithelial sodium channel-mediated sodium transport. Journal of Biological Chemistry 280 39970-39981.

Thomson AB \& Keelan M 1986 The development of the small intestine. Canadian Journal of Physiology and Pharmacology 64 13-29.

Zhang W, Yang N \& Shi XM 2008 Regulation of mesenchymal stem cell osteogenic differentiation by glucocorticoid-induced leucine zipper (GILZ). Journal of Biological Chemistry 283 4723-4729.

Zhao B, Koon D \& Bethin KE 2006 Identification of transcription factors at the site of implantation in the later stages of murine pregnancy. Reproduction 131 561-571.

Received in final form 7 November 2008

Accepted 25 November 2008

Made available online as an Accepted Preprint 25 November 2008 